\title{
Primary Sinus Carcinoma Masquerading as Destructive Periodontitis: Report of a Case
}

\author{
Pillai $\mathbf{H}^{1^{*}}$, Anil $\mathbf{S}^{2}$ and Rajendran $\mathbf{R}^{1}$ \\ ${ }^{1}$ Department of Oral and Maxillofacial Pathology, College of Dentistry, King Saud bin Abdulaziz University for Health Sciences, NGHA, Riyadh, Saudi Arabia \\ ${ }^{2}$ Department of Periodontics and Community Dentistry, College of Dentistry, King Saud University, Riyadh, Saudi Arabia
}

"Corresponding author: Dr. Hari Pillai, BDS, MDS, Department of Oral and Maxillofacial Pathology, College of Dentistry, King Saud bin Abdulaziz University for Health Sciences, NGHA, P. O. Box: 22490, Riyadh 11426, Saudi Arabia, Tel: 00966500197223; E-mail: codriyadh@gmail.com

Rec date: Apr 22, 2014, Acc date: Jul 28, 2014, Pub date: Jul 30, 2014

Copyright: (c) 2014 Pillai H, et al. This is an open-access article distributed under the terms of the Creative Commons Attribution License, which permits unrestricted use, distribution, and reproduction in any medium, provided the original author and source are credited

\begin{abstract}
Carcinomas of the maxillary sinus are uncommon and comprise $3 \%$ of all head and neck cancers, and $80 \%$ of all paranasal sinus cancers. Squamous cell carcinoma is the most common malignant tumor at this site, representing $60 \%-90 \%$ of the total cases. A case of occult carcinoma of the maxillary antrum with features of destructive periodontitis in a 48 year old female is presented. The case reported here remained undiagnosed due to failure of manifestation of associated signs and symptoms primarily overshadowed with those of tooth related pathoses. The need of clinical suspicion of malignancy arising from maxillary sinus should be taken into consideration whenever dealing with non-specific oral symptoms likes pathologic tooth mobility especially in the upper jaw. The case reported here failed to manifest salient clinical signs and symptoms of the tumor and areas of tumor involvement except perhaps of the jaw. The need for early screening and management protocols for effective control of the lesion cannot be overemphasized.
\end{abstract}

Keywords: Squamous cell carcinoma; Maxillary sinus; Neoplasms; Diagnosis; Periodontitis

\section{Introduction}

Primary carcinoma of the maxillary antrum is a relatively rare neoplasm and accounts for a small percentage $(0.2 \%)$ of malignancies in human and constitutes approximately $1.5 \%$ of all head and neck malignancies [1-3]. This includes primary sinonasal neoplasms like squamous cell carcinoma, nasopharyngeal adenocarcinoma, lymphoma, primary sinonasal melanoma, carcinoma of minor salivary gland origin as well as metastatic diseases [4]. The incidence varies between populations, with more cases reported in Asian countries $[5,6]$. Men are more prone to this type of malignancy which occurs mostly in their sixth or seventh decades of life [7]. Majority of cases are asymptomatic in the early stages and mimic sinusitis. Most patients are diagnosed at an advanced stage with the tumor mass filling the entire antral space and perforating through the surrounding bone [8].

Carcinoma of the maxillary sinus is one of the neoplasms that is difficult to treat and carries a poor prognosis [9]. The reasons for the poor treatment outcome include the anatomic proximity of the nasal cavity and paranasal sinuses to vital structures such as skull base, brain, orbit etc. The complexity of the location can make complete resection an almost impossible task. Radiation therapy, conservative surgery and chemotherapy in a variety of combinations and sequences are considered with a relatively dismal prognosis $[7,10]$.

In routine clinical practice, mobility of teeth is usually attributed to dental causes like periodontal and periapical lesions. But it is a rare event for malignant sinus neoplasms to present with dental mobility. A case of carcinoma arising primarily from the sinus mucosa, manifesting as contiguous teeth mobility and associated symptoms is reported here.

\section{Case Report}

A 48 year old woman attended a dental clinic complaining of excessive mobility of left maxillary molars. Since the teeth appeared to be periodontally involved and the patient not willing for periodontal treatment, extraction was planned for the patient. After taking the medical history which was noncontributory, teeth 26 and 27 were extracted under local anesthesia. A soft tissue mass was found attached to the root tips of 26 (Figure 1).

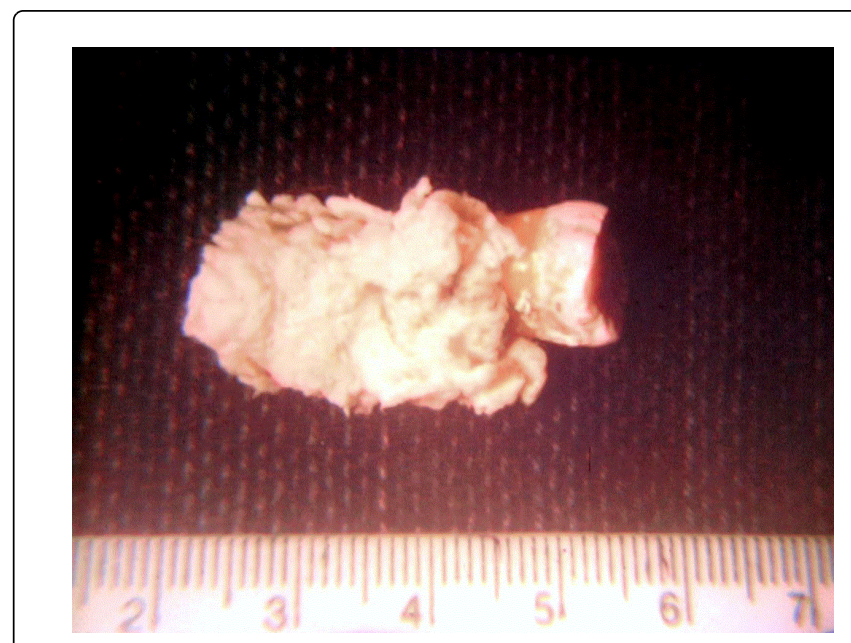

Figure 1: Extracted tooth with the soft tissue mass attached

The specimen was sent for histopathological examination to the Oral pathology department at Noorul Islam College of Dental Sciences, University of Kerala, India. Meanwhile, skull radiographs were ordered and the patient was dismissed after administering 
Citation: $\quad$ Pillai H, Anil S, Rajendran R (2014) Primary Sinus Carcinoma Masquerading as Destructive Periodontitis: Report of a Case. Dentistry 4:

primary wound care. A course of broad spectrum antibiotics and analgesics were prescribed and instructions were given for a recall visit on the third day of surgery.

Clinical examination on the third day revealed extraction sockets with friable granulation tissue showing no signs of healing (Figure 2). The area adjacent to the extraction socket was mildly painful and tender to palpation. No lymph nodes were detected in the neck region. On radiographic examination (Water's view) the entire left maxillary sinus showed opacification as well as destruction of the inferior, posterior, lateral and medial walls of the sinus (Figure 3).

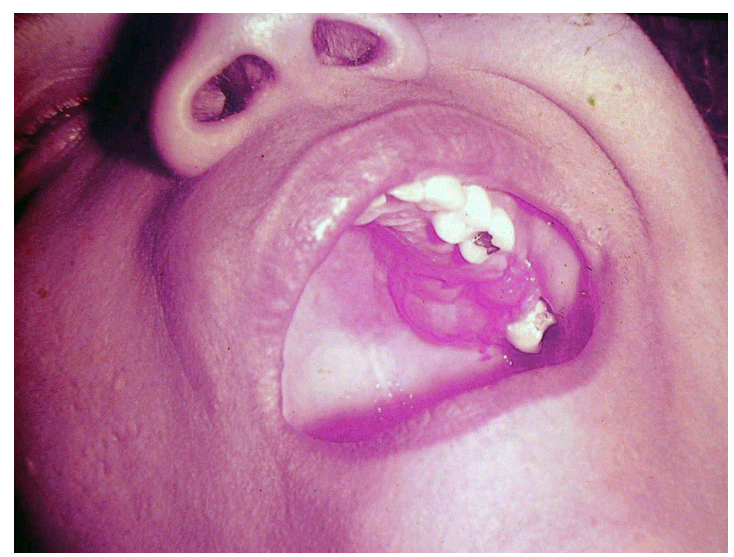

Figure 2: Extraction wound on the third day

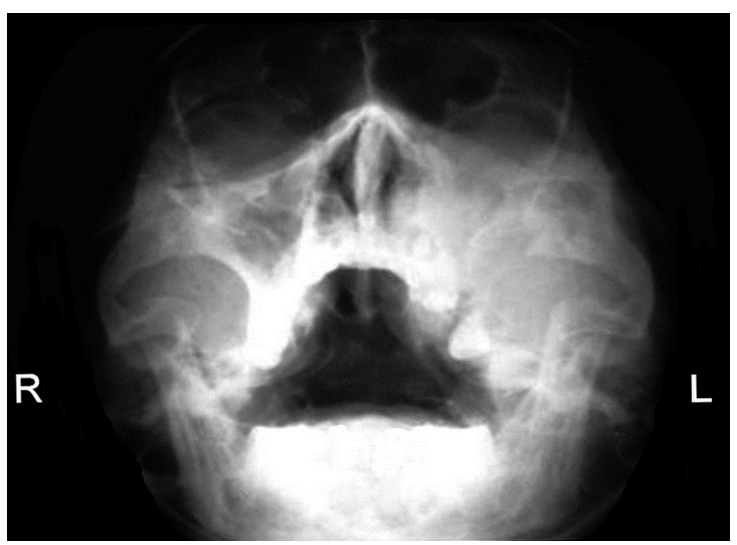

Figure 3: Opacification of left maxillary sinus as seen in Water's view

The patient was referred to the radiology department, where plain computed tomography was performed. The CT scan confirmed the sinus destruction supporting the diagnosis of maxillary antrum carcinoma with invasion into the hard palate, nasal cavity and infratemporal fossa (Figure 4). Macroscopic examination of specimen revealed a firm mass measuring $25 \mathrm{mmx} 15 \mathrm{mmx} 12 \mathrm{~mm}$ that was attached to the roots of the maxillary first molar

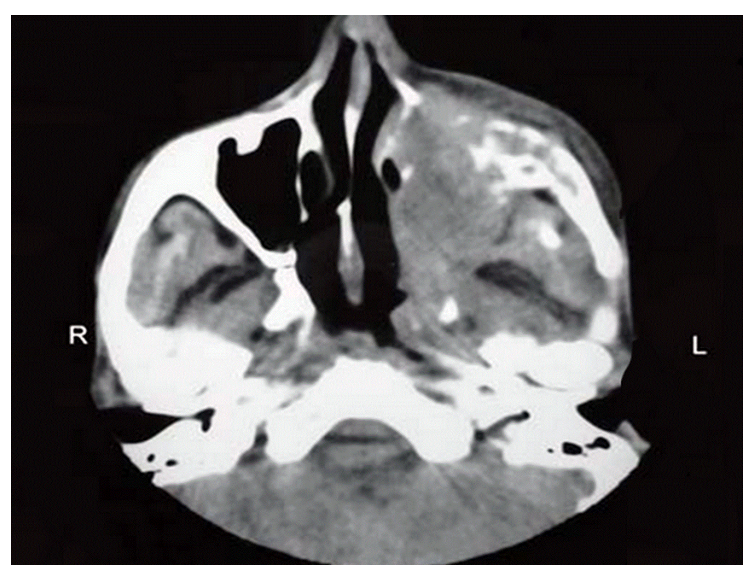

Figure 4: Axial view CT showing expansive lesion centered on the left maxillary sinus

Microscopic examination revealed sheets and nests of cells with obvious origin from squamous epithelium invading the deeper connective tissue. The cells were large with distinct cell membranes. The nuclei of the neoplastic cells exhibited a great deal of variability in shape and size (Figure 5). A diagnosis of moderately differentiated squamous cell carcinoma was made.

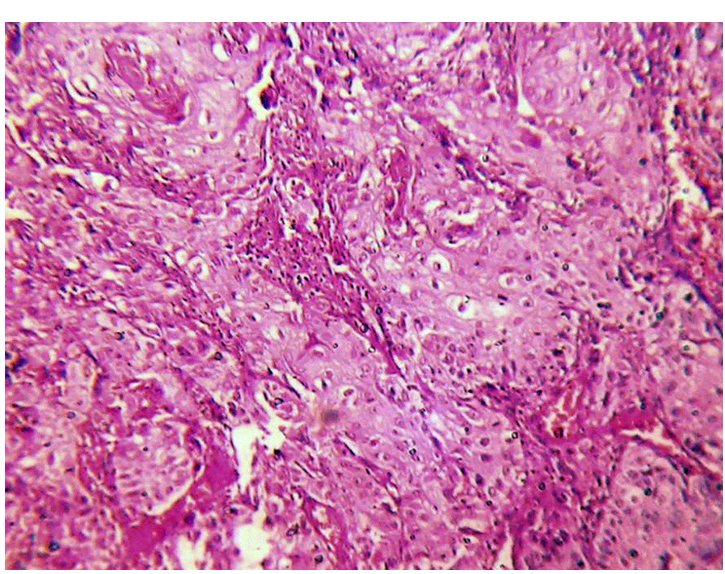

Figure 5: Photomicrograph showing intense pleomorphism and great number of mitoses of epithelial cells. Spindle and round epithelial cells are seen (hematoxilin-eosin, 200x)

The patient was referred to the Surgical Oncology division of Regional Cancer Centre, Trivandrum were she subsequently underwent a left side maxillectomy.

\section{Discussion}

Squamous cell carcinoma constitutes over $80 \%$ of all malignancies that arise in the nasal cavity and paranasal sinuses. Approximately $70 \%$ occurs in the maxillary sinus, $12 \%$ in the nasal cavity, and the remainder in the nasal vestibule and remaining sinuses [11]. The risk factors for maxillary antrum carcinoma are multifactorial, and somewhat controversial. Exposures to nickel dust, mustard gas, thorotrast, isopropyl oil, chromium, or dichlorodiethyl sulfide are 
some of the factors that have shown a link [12]. Studies have shown an association of squamous cell carcinoma with wood dust exposures, which increase the risk upto 21 times [13]. A viral association especially with human papillomavirus (HPV) and Epstein-Barr virus (EBV) infection leading to the malignant transformation of inverted papillomas of the antrum have been reported [14].

The clinical presentation of carcinoma of the maxillary sinus can be highly variable. Approximately, $40-60 \%$ of the cases exhibit facial asymmetry, oral cavity swelling and tumor extension medially to the nose, superiorly to orbit and ethmoidal sinus and anterolateral extension to soft tissues and cheek. Inferiorly growing tumors can involve the maxillary sinus floor, dental alveolus and palate whereas posteriorly growing tumor may reach the pterygopalatine fossa and pterygoid muscles [15]. There is also the possibility of small sized tumors getting wrongly diagnosed for chronic sinusitis, nasal polyp etc. [16]. Pathologies involving the sinonasal complex usually manifest as maxillary swelling, epistaxis, nasal obstruction or discharge, diplopia and proptosis of the eye. The common symptoms associated with antral carcinoma are pain (59\%), followed by oral symptoms (40\%), facial swelling (38\%), nasal obstruction (35\%) and epistaxis (25\%) [7]

In the absence of these physical signs, the clinician may overlook the possibility of a malignant disease [17]. In the present case, the patient had none of the above mentioned signs, except abnormal mobility of upper first molar negating the suspicion of malignancy. Moreover the present case had no palpable lymph nodes in the drainage area. This could be explained due to the poor lymphatic drainage of the maxillary sinus and also by the relatively inaccessible location of the affected lymph nodes to clinical examination. In the neck region the site distribution of lymph node metastasis is dependent on factors like tumor site, contiguous structures and presence of a rich capillary network [18].

Carcinoma of the maxillary antrum can present itself as a diagnostic challenge to the general dental practitioner and can occasionally complicate the outcome of routine dental treatment. Patients presenting with pain and swelling of jaws, when examined clinically will reveal lesions of dental origin, of either pulpal or periodontal pathology. However the dentist must always consider the possibility of non-dental causes for common complaints like pain and mobility of teeth especially of the upper jaw.

Signs and symptoms that should alert the clinician to the possibility of a malignant tumor include paresthesia, radiographic evidence of irregular bone resorption and localized irregular widening of the periodontal ligament [19]. Even though altered sensation (paresthesia) is an ominous sign in malignancies involving maxillary antrum, it was absent in the present case contributing to the general dental practitioner's inability to arouse suspicion of a possible neoplasm in the location.

Panoramic radiography is usually made use of by the majority of clinicians for the diagnosis of antral carcinoma. While it is adequate to identify destruction of the boundaries of maxillary antrum particularly the inferior antral wall, this imaging modality has got its own limitations when it comes to showing evidence of early bone destruction [20]. Computerized tomography and magnetic resonance imaging (MRI) are the tools of choice in such situations. Invasion of structures beyond the site of origin is best characterized by CT and MRI studies. The computerized tomogram provides more details of bone invasion than magnetic resonance imaging [16].
Malignancies involving the maxillary sinus are usually diagnosed in the advanced stages and so determining its primary locale of origin can be difficult. Because of the non-specific symptoms, maxillary sinus carcinomas tend to remain localized for a long time before they get diagnosed resulting in inadvertent involvement of adjacent structures and delay in treatment planning [15].

\section{Conclusion}

Malignant neoplasms of the maxillary antrum can be in a fairly advanced stage when the patient first reports before the clinician, even though the duration of symptoms may be less. The tumor is usually more extensive than what the clinical examination suggests and conventional radiography is insufficient to note the extent of the invasion. In this context, C. T. Scan and MRI are valuable aids to know the extent of tumor spread and should be used more frequently.

An early diagnosis can be made possible by increasing the awareness of the people regarding the symptomatology and encouraging them to seek medical attention at the beginning. Moreover clinicians should maintain a high degree of suspicion while treating patients with prolonged and unexplained dental and nasal problems and if possible subjecting them to radiological screening and tissue biopsy.

\section{References}

1. Nunez F, Suarez C, Alvarez I, Losa JL, Barthe P, et al. (1993) Sino-nasal adenocarcinoma: epidemiological and clinico-pathological study of 34 cases. J Otolaryngol 22: 86-90.

2. Rajendran R (2012) Benign and malignant Tumors of oral cavity: Carcinoma of the maxillary sinus. Elsevier India.

3. Franchi A, Moroni M, Massi D, Paglierani M, Santucci M (2002) Sinonasal undifferentiated carcinoma, nasopharyngeal-type undifferentiated carcinoma, and keratinizing and nonkeratinizing squamous cell carcinoma express different cytokeratin patterns. Am J Surg Pathol 26: 1597-1604.

4. Goldenberg D, Golz A, Fradis M, Martu D, Netzer A, et al. (2001) Malignant tumors of the nose and paranasal sinuses: a retrospective review of 291 cases. Ear Nose Throat J 80: 272-277.

5. Robin PE, Powell DJ, Stansbie JM (1979) Carcinoma of the nasal cavity and paranasal sinuses: incidence and presentation of different histological types. Clin Otolaryngol Allied Sci 4: 431-456.

6. Sharma S, Sharma S, Singhal S, Mehra Y, Gupta B, et al. (1991) Carcinoma of the maxillary antrum-A 10 year experience. Ind J Otolaryngol 43: 191-194.

7. Waldron JN, O'Sullivan B, Gullane P, Witterick IJ, Liu F,F et al. (2000) Carcinoma of the maxillary antrum: a retrospective analysis of 110 cases. Radiother Oncol 57: 167-173.

8. Bhattacharyya N (2003) Factors affecting survival in maxillary sinus cancer. J Oral Maxillofac Surg 61: 1016-1021.

9. Carrillo JF, Guemes A, Ramirez-Ortega MC, Onate-Ocana LF (2005) Prognostic factors in maxillary sinus and nasal cavity carcinoma. Eur J Surg Oncol 31: 1206-1212.

10. Myers LL, Nussenbaum B, Bradford CR, Teknos TN, Esclamado RM, et al. (2002) Paranasal sinus malignancies: an 18-year single institution experience. Laryngoscope 112: 1964-1969.

11. Tiwari R, Hardillo JA, Mehta D, Slotman B, Tobi H, et al. (2000) Squamous cell carcinoma of maxillary sinus. Head Neck 22: 164-169.

12. Luce D, Gerin M, Leclerc A, Morcet JF, Brugere J, et al. (1993) Sinonasal cancer and occupational exposure to formaldehyde and other substances. Int J Cancer 53: 224-231. 
Citation: $\quad$ Pillai H, Anil S, Rajendran R (2014) Primary Sinus Carcinoma Masquerading as Destructive Periodontitis: Report of a Case. Dentistry 4: 251. doi:10.4172/2161-1122.1000251

Page 4 of 4

13. Bornholdt J, Hansen J, Steiniche T, Dictor M, Antonsen A, et al. (2008) $\mathrm{K}$-ras mutations in sinonasal cancers in relation to wood dust exposure. BMC cancer 8: 53.

14. Katori H, Nozawa A, Tsukuda M (2005) Markers of malignant transformation of sinonasal inverted papilloma. Eur J Surg Oncol 31: 905-911.

15. Manrique RD, Deive LG, Uehara MA, Manrique RK, Rodriguez JL, et al (2008) Maxillary sinus cancer review in 23 patients treated with postoperative radiotherapy. Acta Otorrinolaringol Esp 59: 6-10.

16. Som PM, Brandwein M (1996) Sinonasal cavities. Inflammatory diseases, tumors, fractures and postoperative findings. Mosby, St Louis.

17. Hone SW, O'Leary TG, Maguire A, Burns H, Timon CI (1995) Malignant sinonasal tumours: the Dublin Eye and Ear Hospital experience. Ir J Med Sci 164: 139-141.
18. Stern S, Hanna E (1996) Cancer of the nasal cavity and paranasal sinuses. (3rdedn), WB Saunders Co, Philadelphia.

19. Georgiou AF, Walker DM, Collins AP, Morgan GJ, Shannon JA, et al. (2004) Primary small cell undifferentiated (neuroendocrine) carcinoma of the maxillary sinus. Oral Surg Oral Med Oral Pathol Oral Radiol Endod 98: 572-578.

20. Lilienthal B, Punnia-Moorthy A (1991) Limitations of rotational panoramic radiographs in the diagnosis of maxillary lesions. Case report. Aust Dent J 36: 269-272. 